\section{COVID-19 and TEN Treated With IVIG and Total Plasma Exchange: Simultaneous Systemic Treatment for Both Diseases}

Krajewski A ${ }^{1}$, Mlynska-Krajewska E ${ }^{1}$, Kaczynska K ${ }^{1}$, Strużyna J ${ }^{2}$, Mazurek $\mathrm{MJ}^{1}$

${ }^{I}$ West Pomeranian Center for Severe Burns and Plastic Surgery, Gryfice, Poland

${ }^{2}$ Eastern Burns and Reconstructive Surgery Center, Lęczna, Poland

J Investig Allergol Clin Immunol 2021; Vol. 31(6): 522-523 doi: $10.18176 /$ jiaci.0692

Key words: COVID-19. IVIG. TPE. SARS-CoV-2. Systemic.

Palabras clave: COVID-19. Infusión inmunoglobulina. Intercambio total de plasma. SARS-CoV-2. Sistémico.

Toxic epidermal necrolysis (TEN) is a rare but potentially fatal systemic disease that mainly affects the skin. The plethora of known causal factors includes antibiotics, nonsteroidal anti-inflammatory drugs, and antihistamines). Several treatment regimens have been proposed, the most common being corticosteroids and cyclosporine [1-3]. Given that, since 2019, we have all been struggling with the pandemic environment brought about by the SARS-CoV-2 virus infection (COVID-19) [4], these diseases have received little attention in the literature $[5,6]$. We present a case of concomitant TEN and COVID-19 treated with intravenous immunoglobulin (IVIG) infusion and total plasma exchange (TPE). The treatment protocol consisted of daily TPE followed by an IVIG infusion [7]. A 76-year-old woman was admitted to our unit with a positive COVID 19 result (GeneFInder COVID-19 Plus RealAMP). The RdRp, N, and E genes were present. Her medical history included hypertension and type 2 diabetes mellitus. She had a long history of treatment with indapamide $1.5 \mathrm{mg}$ (Tertensif SR, Servier), ramipril $5 \mathrm{mg}$ (Polpril, Polpharma), and metformin $3 \times 850 \mathrm{mg}$ (Siofor, BerlinChemie AG). Two days before admission, she had contacted her primary care physician because of flu-like symptoms and abdominal pain. Examination revealed no specific findings, fever, or tachypnea. The patient's symptoms were treated with intramuscular injection of metamizole 1.0 (Pyralgin, Polpharma), and a swab was taken for COVID-19. She was then discharged home to self-isolate until the test results were known. Skin and mucosal lesions began to develop 2 days after her visit to primary care. The patient was admitted to the unit with typical COVID-19 symptoms (fever, respiratory distress) from her home, where she had been staying in isolation, owing to the positive test result. There was no evident cause of TEN (in the absence of a recently taken drug), although the most possible explanation seems to have been metamizole ( 2 days from administration to onset of TEN). The total body surface area affected by erythematosus blistering was $70 \%$, with involvement of the oral and vaginal mucosa (Figure). The

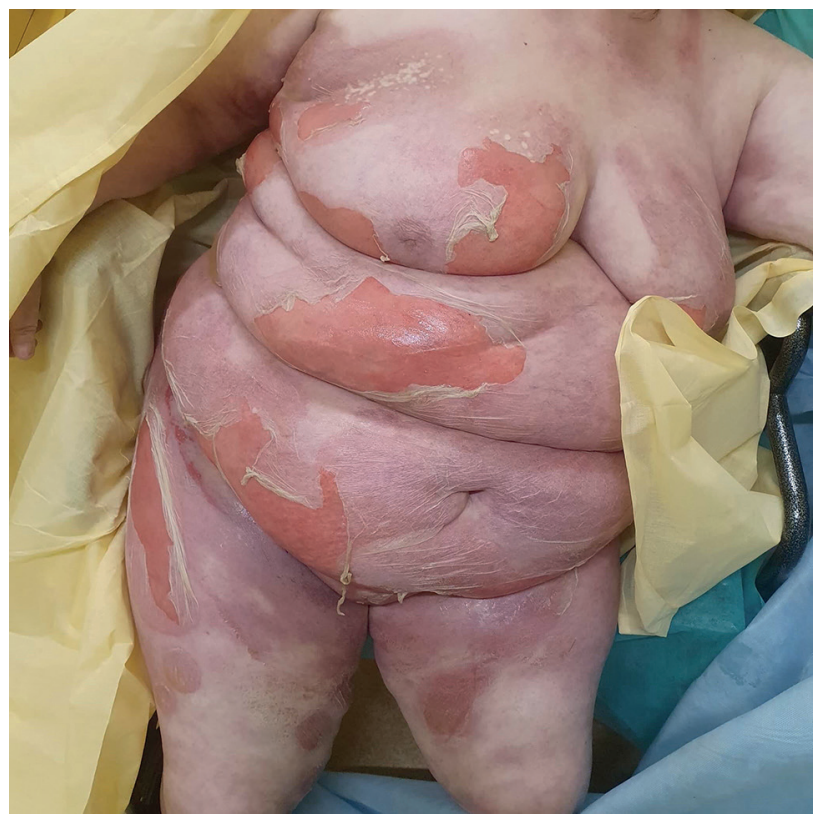

Figure. Lesions on admission.

diagnosis of TEN was confirmed by a consultant dermatologist. Biopsy revealed subepidermal bullae, epidermal necrosis, and moderate dermal infiltration with lymphocytes. The patient was obese (body mass index, 38.06) and was admitted with respiratory distress (non-rebreathing mask oxygen $6 \mathrm{~L} / \mathrm{min}$ and blood oxygen saturation of $80 \%$ ). Her SCORTEN score on admission was 4. Laboratory test results on the day of admission were as follows: C-reactive protein, $138 \mathrm{mg} / \mathrm{L}$; procalcitonin, $0.9 \mathrm{ng} / \mathrm{mL}$; D-dimer, $3.65 \mu \mathrm{g} / \mathrm{mL}$. The patient's wounds were treated mainly with Suprathel (PolyMedics Innovations $\mathrm{GmbH}$ ). However, owing to failure of adhesion due to body pressure, Aquacel Ag (Convatec) was applied on her back. Systemic treatment was provided with daily TPE followed by an IVIG infusion. She received a total of 5 cycles of TPE with 50 fresh frozen plasma units and $90 \mathrm{~g}$ of IVIG. Sepsis caused by Escherichia coli during hospitalization was treated with targeted antibiotic therapy (levofloxacin and cefuroxime). Every day, the patient also received enoxaparin $2 \times 0.4 \mathrm{~mL}$ (Clexane, Sanofi), ramipril $5 \mathrm{mg}$ (Polpril, Polpharma), metformin $3 \times 850 \mathrm{mg}$ (Siofor, Berlin-Chemie $\mathrm{AG}$ ), and furosemide $2 \times 20 \mathrm{mg}$ (Furosemidum, Polfarmex). Her skin lesions had stabilized on day 7. External oxygenation was stopped on day 8 . Her laboratory parameters normalized, and, on the day of discharge (day 14), C-reactive protein was $21 \mathrm{mg} / \mathrm{L}$ and procalcitonin $0.1 \mathrm{ng} / \mathrm{mL}$. Her skin had almost fully healed, with small patches of erythema and superficial epidermal exfoliation. We believe that IVIG and TPE could ameliorate the bradykinin or cytokine storm associated with COVID-19 by immunomodulating cytokine activity (IL-6, TNF- $\alpha$ ) and by eliminating exogenous antigens [8-10]. We believe that this systemic treatment had a positive effect on both diseases and stopped the impending deterioration caused by dysregulation of the immune system. Nevertheless, broader implementation of IVIG and TPE in COVID-19 needs to be 
evaluated in terms of its potential benefits and cost-benefit ratio in a multicenter, randomized trial.

\section{Acknowledgments}

The patient gave her written informed consent for the publication of her photos.

\section{Funding}

The authors declare that no funding was received for the present study.

\section{Conflicts of Interest}

The authors declare that they have no conflicts of interest.

\section{References}

1. Torres-Navarro I, Briz-Redon A, Botella-Estrada R. Systemic therapies for Stevens-Johnson Syndrome and Toxic Epidermal Necrolysis: a SCORTEN-based systematic review and metaanalysis. J Eur Acad Dermatol Venereol. 2021;35(1):159-71.

2. McPherson T, Exton LS, Biswas $S$, Creamer D, Dziewulski $P$, Newell $L$, et al. British Association of Dermatologists guidelines for the management of Stevens-Johnson syndrome/toxic epidermal necrolysis in children and young people 2018. Br J Dermatol. 2019;181(1):37-54.

3. Teo SL, Santosa A, Bigliardi PL. Stevens-Johnson Syndrome/ Toxic Epidermal Necrolysis Overlap Induced by Fexofenadine. J Investig Allergol Clin Immunol. 2017;27:191-3.

4. Machhi J, Herskovitz J, Senan AM, Dutta D, Nath B, Oleynikov $M D$, et al. The Natural History, Pathobiology, and Clinical Manifestations of SARS-CoV-2 Infections. J Neuroimmune Pharmacol. 2020;15:359-86.

5. Emadi SN, Hamzelou S, Saffarian Z, Shakoei S. Challenges in the treatment of a patient with toxic epidermal necrolysis associated with COVID-19: A case report. Dermatol Ther. 2021;34(1):e14656.

6. Saha M, D'Cruz A, Paul N, Healy R, Collins D, Charles DA, et al. Toxic epidermal necrolysis and co-existent SARS-CoV-2 (COVID-19) treated with intravenous immunoglobulin: 'Killing 2 birds with one stone'. J Eur Acad Dermatol Venereol. 2021;35(2):e97-8.

7. Krajewski A, Mazurek MJ, Mlynska-Krajewska E, Piorun K, Knakiewicz M, Markowska M. Toxic Epidermal Necrolysis Therapy with TPE and IVIG-10 Years of Experience of the Burns Treatment Center. J Burn Care Res. 2019;40:652-7.

8. Soy M, Keser G, Atagunduz P, Tabak F, Atagunduz I, Kayhan S. Cytokine storm in COVID-19: pathogenesis and overview of anti-inflammatory agents used in treatment. Clin Rheumatol. 2020;39:2085-94.

9. Mahmudpour M, Roozbeh J, Keshavarz M, Farrokhi S, Nabipour I. COVID-19 cytokine storm: The anger of inflammation. Cytokine. 2020;133:155151.
10. Narita YM, Hirahara K, Mizukawa Y, Kano Y, Shiohara T. Efficacy of plasmapheresis for the treatment of severe toxic epidermal necrolysis: Is cytokine expression analysis useful in predicting its therapeutic efficacy? J Dermatol. 2011;38:23645.

- Manuscript received February 12, 2021; accepted for publication April 13, 21.

Maciej Mazurek

ul. Niechorska 27

72-300 Gryfice, Poland

E-mail-maciek.j.mazurek@gmail.com 